\title{
Economics, epidemiology and outcomes
}

This month's issue of The Journal of Laryngology \& Otology provides much room for thought. The economic impact of recurrent respiratory papilloma, a benign disease with a natural history that is relapsing and remitting over several years, has not previously been estimated in the UK. Harrison et al. have now done so and the costs are significant. ${ }^{1}$ The case for prevention and combined concurrent adjunctive treatment remains strong and holds promise. $^{2}$

The hypothesis that the age of onset of Ménière's disease is increasing as the elderly take to work with its attendant stress $^{3}$ has not been corroborated by Van Esch and colleagues' epidemiological study from the Netherlands. ${ }^{4}$ Ménière's disease has a peak incidence between 40 and 69 years in the Netherlands, as in most other countries. ${ }^{5}$

The age for closure of a child's perforated eardrum has been a controversial matter. ${ }^{6}$ Singh et al. show that the comparative outcomes of tympanoplasty in younger children are no different from those in older children. ${ }^{7}$ In cases of small vestibular schwannomas with serviceable hearing, Peng and Wilkinson's systematic review on the outcomes of microsurgery in relation to observation and stereotactic radiation shows that, for patients under the age of 65 years, microsurgery via the middle fossa offers durable preservation of hearing. ${ }^{8}$ One of the vicissitudes that occasionally occurs in thyroid surgery is incidental parathyroidectomy. Hone et al. report that concurrent neck dissection is an independent predictor of incidental parathyroidectomy and increases the risk by a factor of four. ${ }^{9}$

MUSHEER HUSSAIN
EDWARD FISHER
ROBIN YOUNGS
JONATHAN FISHMAN
Senior Editors

References

1 Harrison A, Montgomery J, Macgregor FB. Economic impact of recurrent respiratory papillomas in a UK adult population. $J$ Laryngol Otol 2016;130:645-9

2 Kim HT, Baizhumanova AS. Is recurrent respiratory papillomatosis a manageable or curable disease? Laryngoscope 2016;126:1359-64

3 Shojaku H, Watanabe Y, Fujisaka M, Tsubota M, Kobayashi K, Yasumura $\mathrm{S}$ et al. Epidemiologic characteristics of definite Ménière's disease in Japan. A long-term survey of Toyama and Niigata prefectures. ORL J Otorhinolaryngol Relat Spec 2005; 67:305-9

4 van Esch BF, van Benthem PP, van der Zaag-Loonen HJ, Bruintjes TD. Age of onset of Ménière's disease in the Netherlands: data from a specialised dizziness clinic. J Laryngol Otol 2016;130:624-7

5 Lüscher M, Theilgaard S, Edholm B. Prevalence and characteristics of diagnostic groups amongst 1034 patients seen in ENT practices for dizziness. J Laryngol Otol 2014;128:128-33

6 Carr SD, Strachan DR, Raine CH. Factors affecting myringoplasty success. J Laryngol Otol 2015;129:23-6

7 Singh GB, Arora R, Garg S, Kumar S, Kumar D. Paediatric tympanoplasty: comparative study between patients aged 5-8 years and those aged over 14 years. J Laryngol Otol 2016;130:635-9

8 Peng KA, Wilkinson EP. Optimal outcomes for hearing preservation in the management of small vestibular schwannomas. $J$ Laryngol Otol 2016;130:606-10

9 Hone RW, Tikka T, Kaleva AI, Hoey A, Alexander V, Balfour A et al. Analysis of the incidence and factors predictive of inadvertent parathyroidectomy during thyroid surgery. J Laryngol Otol 2016;130:669-73 